\title{
Construindo Saberes em Psicologia: O Desafio de Articular Diferentes Teorias e Práticas ${ }^{1}$
}

\author{
Terezinha Féres-Carneiro ${ }^{2}$ \\ Departamento de Psicologia da Pontifícia Universidade Católica do Rio de Janeiro, \\ Rio de Janeiro, Rio de Janeiro, Brasil
}

\begin{abstract}
Resumo
Neste texto, apresentado na Conferência de Abertura da $44^{a}$ Reunião Anual da Sociedade Brasileira de Psicologia (SBP), proferida em Ribeirão Preto, em 21/10/14, discutem-se articulações entre diferentes enfoques teórico-técnicos, construídas pela autora a partir de sua inserção na academia e na prática clínica. A história de um percurso de 42 anos, como docente-pesquisadora e como psicóloga clínica, é relatada, ressaltando o modo indissociável de conceber tais funções. São apresentados resultados de pesquisas sobre avaliação familiar, casamento, separação, recasamento e psicoterapia de família e casal, assim como sobre conjugalidades e parentalidades contemporâneas. Ao longo do texto são explicitadas possibilidades de diferentes abordagens teóricas se complementarem na investigação e na clínica com famílias e casais. Abrindo mão de um purismo tradicional na análise dos dados, nos estudos de validação do "Questionário sobre a Conjugalidade dos Pais (QCP)", a autora propõe um diálogo entre duas áreas, aparentemente incompatíveis: a Psicometria e a Psicanálise, reafirmando seu propósito de buscar articulações teóricas na pesquisa e na prática psicológicas. Tal proposta vai ao encontro do tema da $44^{\mathrm{a}}$ Reunião Anual da SBP: "Onde a diversidade se encontra".
\end{abstract}

Palavras-chave: Pesquisa, prática clínica, articulações teóricas.

\section{Building Knowledge in Psychology: The Challenge of Articulating Different Theories and Practices}

\begin{abstract}
In this article - presented during the Opening Conference of the $44^{\text {th }}$ Brazilian Psychological Society (SBP) Annual Meeting, held in Ribeirão Preto, in 10/21/14 - the author discusses the articulations between different theoretical and technical approaches built by her from professional experiences within the academy and clinical practice. The story of a 42-year-journey - both as a professor/researcher and as a clinical psychologist - is narrated, highlighting the inseparable conception of such roles. The author presents results from surveys regarding family assessment, marriage, divorce, remarriage, and family and couple's psychotherapy, as well as contemporary conjugality and parenthood. The article features the possibilities in which different theoretical approaches can complement themselves during research and clinical practice with families and couples. Traditional purism in data analysis is waived during the "Parent Conjugality Questionnaire" (QCP, in Portuguese) validation studies, favoring a closer dialogue between two seemingly incompatible areas - Psychometrics and Psychoanalysis - reaffirming the
\end{abstract}

Conferência de Abertura da $44^{\mathrm{a}}$ Reunião Anual da Sociedade Brasileira de Psicologia (SBP), proferida pela autora, em Ribeirão Preto, em 21/10/14.

2 Endereço para correspondência: Departamento de Psicologia, Pontifícia Universidade Católica do Rio de Janeiro, Centro de Teologia e Ciências Humanas, Rua Marquês de São Vicente, 225, Gávea, Rio de Janeiro, RJ, Brasil 22453-900. E-mail: teferca@puc-rio.br 
author's purpose of seeking theoretical articulation between psychological research and clinical practice. This proposal meets the 44th SBP Annual Reunion's theme: "Where Diversity is Found".

Keywords: Research, clinical practice, theoretical articulation.

\section{Construyendo Saberes en Psicología: El Desafío de Articular Diferentes Teorías y Prácticas}

\section{Resumen}

En este artículo, presentado en la Conferencia de Apertura de la 44a Reunión Anual de la Sociedad Brasileña de Psicología (SBP), proferida en Ribeirão Preto, en el 21/10/14, se discuten las articulaciones entre diferentes enfoques teóricos-técnicos construidas por la autora a partir de su inserción en la academia y en la práctica clínica. La historia de un recorrido de 42 años, como docente-investigadora y como psicóloga clínica, es relatada resaltando el modo indisociable de concebir tales funciones. Son presentados resultados de investigaciones sobre evaluación familiar, matrimonio, separación, recasamiento y psicoterapia de familia y pareja, así como sobre conyugalidades y parentalidades contemporáneas. A lo largo del texto son explicitadas posibilidades de que diferentes abordajes teóricos se complementen en la investigación y en la clínica con familias y parejas. Renunciando al purismo tradicional en el análisis de los datos, en los estudios de validación del "Cuestionario sobre la Conyugalidad de los Padres" (QCP, en portugués), la autora propone un diálogo entre las dos áreas, aparentemente incompatibles: la Psicometría y el Psicoanálisis, reafirmando su propósito de buscar articulaciones teóricas en la investigación y práctica psicológicas. Tal proposición está en sintonía con el tema de la $44^{\mathrm{a}}$ Reunión Anual de la SBP: "Donde la diversidad se encuentra".

Palabras clave: Investigación, práctica clínica, articulaciones teóricas.

Inicialmente, eu gostaria de agradecer ao professor doutor Ricardo Gorayeb, Presidente da Sociedade Brasileira de Psicologia, e a todos os membros da Diretoria e da Comissão Científica, pelo convite para proferir a Conferência de Abertura da $44^{\text {a }}$ Reunião Anual da Sociedade Brasileira de Psicologia (SBP), que comemora também os 50 anos de fundação do Departamento de Psicologia da Faculdade de Filosofia, Ciências e Letras da Universidade de São Paulo (USP), onde a Sociedade foi fundada. Minha relação de afeto com a SBP começou a ser construída na $2^{\mathrm{a}}$ Reunião Anual, realizada em outubro de 1972. Eu cursava o Mestrado em Psicologia Clínica da Pontifícia Universidade Católica do Rio de Janeiro (PUC-Rio) e fui convidada por Yolande Lisbona, que tinha sido minha professora de Método Científico, para vir com ela à Reunião Anual da Sociedade de Psicologia de Ribeirão Preto, precursora da Sociedade Brasileira de Psicologia. A partir daí, participei das atividades de inúmeras Reuniões Anuais, apresentando trabalhos, ministrando cursos, coordenando Simpósios e Mesas Redondas, e ministrando Conferências, tendo sido também Representante Regional da SBP no Rio de Janeiro, e ocupando atualmente o cargo de Editora-Chefe da Revista Temas, editada pela Sociedade Brasileira de Psicologia. Foi, portanto, com muita honra e alegria que aceitei o convite para proferir esta Conferência de Abertura da $44^{\mathrm{a}}$ Reunião Anual, que tem como tema "Onde a diversidade se encontra".

Antes de compartilhar com vocês um pouco do meu percurso de pesquisadora e de psicóloga clínica, marcado também, em muitos momentos, pelo encontro de diferenças e por decorrentes propostas de articulação, queria dizer que a tendência a promover articulações está presente, desde muito cedo, na minha história. Sabemos que não é por acaso que escolhemos uma profissão, como também não é por acaso que escolhemos o modo como vamos exercê-la. Desde muito jovem, entre os familiares, no grupo de amigos, entre os colegas do colégio, 
eu era quase sempre solicitada para ouvir histórias de relacionamentos, solucionar conflitos, mediar diferenças, conciliar posições. Chegada a hora do vestibular, não tive dúvidas: sabia que queria cursar Psicologia na PUC-Rio. Da escola fundamental à universidade, fui sempre escolhida como representante da turma, e no exercício desta função, quase sempre, minha principal tarefa era a de articular diferenças.

Estar, ao longo de 42 anos de vida profissional, me dedicando, com a mesma paixão, à academia e à clínica provoca, muitas vezes, a indagação de muitos colegas. A dicotomia entre pesquisa e prática profissional em Psicologia e as possibilidades de articulação entres estas duas atividades, que intrigam alguns membros da comunidade acadêmica, foram discutidas por alguns pesquisadores da área da Psicologia no Brasil (Féres-Carneiro, 1993, 2008; Piccinini, 1996), que ressaltam a necessidade de se desenvolver uma concepção de mutualidade entre ciência e profissão em psicologia, e uma postura, na universidade, que promova a integração entre pesquisa e prática profissional desde os primeiros anos do curso de graduação, baseada no pluralismo metodológico. É importante que se estreitem, cada vez mais, as relações entre a academia e a profissão de psicólogo, considerando a responsabilidade da universidade na crítica e na produção do conhecimento em qualquer das áreas de aplicação da Psicologia.

A mutualidade entre a clínica e a pesquisa e a busca por articulações teórico-técnicas no exercício das funções de pesquisadora e de psicoterapeuta de família e casal, sempre estiveram presentes desde o início da minha formação. Meu interesse pelo diagnóstico familiar e pela psicoterapia de família surgiu no final do curso de graduação. No Curso de Especialização em Arte-Diagnóstico Familiar e em Psicoterapia de Família, concluído em 1975, tive como professores a Dra. Hanna Kwiatkowska e o Dr. Joe Griffs, ambos da George Washington University, à época, professores visitantes da PUC-Rio. Já nesta ocasião, a busca pela articulação de diferentes enfoques teóricos estava presente na minha formação: Joe Griffs era um terapeuta familiar sistêmico e ministrava, sobretudo, à época, as teorias e técnicas da escola estratégica e da escola estrutural de terapia de família, enquanto Hanna Kwiatkowska utilizava, no seu método de Arte-Diagnóstico-Familiar (1975), a técnica gráfica projetiva que encontra, nos conceitos psicanalíticos, sua principal base de interpretação.

A preocupação em criticar e construir o conhecimento, buscando articulações teóricotécnicas, na clínica de família e casal, que me acompanhou ao longo do Curso de Especialização, permaneceu no Curso de Mestrado, quando elaborei o primeiro método de avaliação das relações familiares construído no Brasil: a Entrevista Familiar Estruturada (Féres-Carneiro, 1975). Este método, fundamentado, sobretudo, nas teorias sistêmicas de família - em pleno desenvolvimento à época - teve, também, na sua concepção, a influência de conceitos psicanalíticos, presentes na fundamentação de algumas de suas tarefas.

No Curso de Doutorado, realizado na Pontifícia Universidade Católica de São Paulo, desenvolvi a pesquisa de validação da Entrevista Familiar Estruturada (Féres-Carneiro, 1981), que passou a ser divulgada como um método clínico capaz de discriminar uma dinâmica familiar dificultadora, de uma dinâmica familiar facilitadora de saúde emocional (Féres-Carneiro, 1983). O método, publicado pela Casa do Psicólogo como teste psicológico (Féres-Carneiro, 2005), se mantém, até hoje, como o único no Brasil construído, com esse objetivo, e tem sido muito utilizado em clínicas-escola e em investigações de dissertações e teses na área de família e casal.

Depois de dez anos de pesquisas realizadas na clínica, sobre estrutura e dinâmica da família, e sobre diagnóstico e terapia familiar, procurando articular conceitos das teorias sistêmicas e das teorias psicanalíticas, no início dos anos 80, meus interesses voltaram-se para o estudo específico do casal parental e do casal conjugal no grupo familiar.

Desenvolvi alguns estudos que discutem a relação entre dificuldades emocionais apresentadas por crianças e conflitos existentes nas interações estabelecidas por seus pais. Dentre estes trabalhos, destaco o estudo sobre sintomas infantis e terapia de casal (Féres-Carneiro, 
1980), cujos resultados mostram que, na grande maioria dos casos, os problemas apresentados pelas crianças encontram suas raízes na relação dos pais e que, quase sempre, é suficiente uma intervenção com o casal para que haja remissão dos sintomas apresentados pelos filhos. Esta é uma posição que continuo defendendo, cada vez mais, e com maior convicção.

Com o propósito de articular diferentes teorias, continuei ampliando meus interesses no estudo da relação conjugal, privilegiando, por um lado, as dimensões de aliança e sexualidade, a partir das postulações de Foucault (1977) e por outro, o estudo das tensões entre individualidade e conjugalidade, fundamentado nas teorias sistêmicas e psicanalíticas de família e casal (Féres-Carneiro, 1987).

Em meados da década de 1980, desenvolvi um grande interesse pelos autores franceses de orientação psicanalítica no trabalho com famílias e casais. Assim, em 1988, realizei um Pós-doutorado, desenvolvendo atividades na Itália e na França. Escolhi trabalhar com a Dra. Ana Maria Nicollò, à época, do Instituto de Terapia Familiar de Roma, e com o Dr. Jean Lemaire, da Universidade de Paris 5 e da Associação de Psicanálise e Sistema Familiar, por serem psicoterapeutas que propõem uma articulação das abordagens sistêmicas com as abordagens psicanalíticas no trabalho com famílias e casais.

Com minha formação como psicoterapeuta de família e casal marcada, em alguns momentos, por influências predominantemente sistêmicas, e, em outros, por influências predominantemente psicanalíticas, tenho colocado em questão a rigidez do purismo destas duas abordagens e defendido a possibilidade de articular diferentes enfoques em terapia de família e de casal.

Em algumas publicações, dentre as quais destaco Féres-Carneiro (1996), discuto esta questão, concordando com autores como Lemaire (1984) e Nicollò (1988). O que vemos nas duas abordagens, é que, de um modo geral, na perspectiva sistêmica, prevalece uma preocupação com o aqui e agora, com a interação e a busca de modificá-la, o que leva a uma desatenção em relação aos processos psíquicos subjacentes. Enquanto na perspectiva psicanalítica, há uma preocupa- ção com a história e os processos inconscientes que estão na origem da disfunção familiar. A proposta de articulação considera que estas duas concepções teóricas, e as práticas delas decorrentes, não podem deixar de considerar que a família e o casal, além de serem grupos auto-regulados, com uma linguagem própria e regras próprias de interação, são movidos, também, por conteúdos inconscientes presentes em sua dinâmica. Assim como Lemaire (1984), considero que é preciso uma tríplice chave de leitura, no trabalho clínico com famílias e casais, que passe pelo intrapsíquico, o interacional e o social.

Sempre lançando mão da possibilidade de articular diferentes teorias, dei continuidade às pesquisas sobre relação amorosa, casamento, separação e terapia de casal, a partir do atendimento clínico, estudando as relações existentes entre a manifestação da individualidade e da conjugalidade, os tipos de escolha amorosa e a manutenção ou a ruptura do casamento. Os resultados desta investigação mostraram que a ruptura ou não do casamento teve uma relação menos significativa com a presença maior ou menor da individualidade e da conjugalidade na interação e com os tipos predominantes de escolha amorosa, estando relacionada, mais significativamente, com a maneira como tais dimensões puderam-se transformar, ao longo do processo terapêutico, e como, dentro de cada tipo de escolha amorosa, o casal, foi capaz de efetuar mudanças no jogo conjunto que envolvia seus membros (Féres-Carneiro, 1995).

No início da década de 1990, uma nova demanda surgiu na minha prática de psicoterapeuta de casal: casais homoafetivos procurando ajuda para resolverem suas dificuldades e seus conflitos interacionais. Comecei a observar, nestes atendimentos, algumas semelhanças e diferenças na vivência da relação amorosa, na heteroafetividade e na homoafetividade. As questões, em geral, começam a me inquietar na clínica e, a partir dela, muitas vezes, desenvolvo pesquisas com a população geral.

Com algumas questões levantadas na clínica, dirigi-me à população geral, para estudar de forma mais ampla estes dois tipos de conjugalidade. Realizei uma investigação com homens e 
mulheres heteroafetivos e homoafetivos dos segmentos médios da população carioca, de diferentes faixas etárias. Os resultados referentes à escolha amorosa mostram que homens e mulheres heteroafetivos valorizam as mesmas qualidades em seus parceiros, ou seja, fidelidade, integridade, carinho e paixão, que foram igualmente valorizadas pelas mulheres homoafetivas, enquanto os homens homoafetivos tendem a enfatizar a importância da atração física e da capacidade erótica de seus parceiros na escolha amorosa (Féres-Carneiro, 1997).

Os resultados referentes à interação conjugal mostram que o relacionamento sexual foi considerado muito importante tanto para os heteroafetivos como para os homofetivos. Em relação à fidelidade, a maioria dos sujeitos de ambos os grupos consideraram-na como de fundamental importância na relação amorosa. Entretanto, entre os homoafetivos, algumas respostas, tanto dos homens como das mulheres, indicaram a alternativa de sexo fora da relação, quer como estímulo para esta, quer como uma possibilidade colocada pela própria definição do relacionamento. No discurso dos homens homoafetivos, foi possível também perceber uma diferença entre infidelidade sexual, não necessariamente considerada como uma traição, e infidelidade amorosa, sempre considerada como uma traição (Féres-Carneiro, 1999).

Os resultados desta investigação possibilitaram que, de volta à clínica de casais, a escuta em relação a estes diferentes tipos de conjugalidade fosse mais contextualizada. Da clínica para a pesquisa, da pesquisa para a clínica, podemos ir tecendo articulações que promovem a crítica e a construção do conhecimento e que enriquecem nossa escuta e nossa intervenção terapêutica.

Dando continuidade à minha atividade de pesquisa, desenvolvi estudos sobre casamento, separação e terapia de casal, com as camadas médias da população carioca. O estudo "Casamento Contemporâneo: Construção da Identidade Conjugal" (Féres-Carneiro, 2001) mostrou que em relação à concepção de casamento, tanto os homens como as mulheres ressaltaram a importância da individualidade na vida a dois, ao mesmo tempo em que enfatizaram a importância do compartilhar e dividir. Todavia, somente as mulheres explicitaram as dificuldades decorrentes do conflito individualidade/conjugalidade na vivência da relação conjugal. Confirmando dados de investigações anteriores (Féres-Carneiro, 1997; Magalhães, 1993), os homens definiram casamento como "constituição de família" e as mulheres como "relação amorosa". Ainda confirmando resultados de outros estudos (Féres-Carneiro, 1987; Jablonski, 1998), constatou-se que os homens estão mais acomodados na relação conjugal e, geralmente, não demonstram necessidades de fazerem mudanças, enquanto as mulheres estão mais inquietas, ressaltando o desejo de buscar transformações que possam melhorar a vivência da conjugalidade.

O estudo sobre "Separação conjugal e a construção das identidades individuais" (Féres-Carneiro, 2003c) investigou como homens e mulheres vivenciam o processo de dissolução do casamento e buscam construir suas identidades individuais, após a separação. Os resultados mostraram que as atitudes e sentimentos de homens e mulheres contrastaram em muitas situações. Delinearam-se, com clareza, um desejo e uma decisão de separação, predominantemente, femininos; o que não significa que a intensidade da dor, vivenciada neste processo, por homens e mulheres, seja diferente. Quando homens e mulheres apontam a infidelidade masculina como uma das causas da separação, ao mesmo tempo em que estão ressaltando que a traição masculina é mais tolerada, culturalmente, do que a feminina, estão também explicitando uma reação maior das mulheres que, traídas, desejam a separação conjugal.

O estudo "Casamento, separação e terapia de casal" (Féres-Carneiro, 2003b), foi desenvolvido na clínica, com casais, atendidos em terapia, cuja demanda continha, como um dos temas, a questão da manutenção ou da ruptura do casamento. Tanto nos casos em que houve ruptura do laço conjugal como naqueles em que não houve, os homens mostraram uma vivência mais negativa da solidão e uma maior dificuldade de ficarem sós, que as mulheres. Quanto à manutenção/dissolução do laço conjugal, constatou-se, em todos os casais, uma grande valorização do casamento, 
apesar da ambivalência que experimentavam em relação à sua manutenção, presente na demanda inicial de psicoterapia de todos os casos estudados. Na grande maioria dos casos, foram as mulheres que manifestaram, com mais intensidade, o desejo de se separarem, e apresentaram alternativas para o processo de dissolução do laço conjugal.

Este dado está presente nos resultados de quase todas as investigações que temos realizado sobre separação, assim como nos casos que tenho atendido na clínica, nos últimos 42 anos: em geral, os homens só manifestam o desejo de separação quando já estão vivenciando um outro relacionamento amoroso. Costumo relacionar este resultado, referente à demanda predominantemente feminina de separação conjugal, tanto na população geral como na população clínica, com o modo como homens e mulheres concebem o casamento. Como mencionei, constatou-se, em investigações anteriores, que os homens, em geral, definem casamento como constituição de família, e as mulheres como relação amorosa. Assim, para as mulheres, quando a relação amorosa não vai bem, a separação parece mais inevitável do que para os homens, cuja concepção de casamento está mais associada à constituição de família. Além disto, vimos também que os homens têm mais dificuldade que as mulheres de ficarem sós, o que pode levá-los a querer se separar, sobretudo, quando já estão vinculados a outras pessoas.

Podemos ver no desenvolvimento destes três estudos, como a intervenção terapêutica pode beneficiar-se dos resultados de pesquisas realizadas com a população não clínica, ao mesmo tempo em que as questões suscitadas na clínica inspiram a formulação de pesquisas com a população geral, que enriquecem a crítica e a produção do conhecimento. É importante não esquecer, também, que o exercício da clínica envolve uma atitude permanente de pesquisa.

A investigação seguinte, intitulada "Conjugalidade dos pais e projeto de vida dos filhos frente ao laço conjugal", teve como objetivo estudar as relações existentes entre o casamento dos pais, tal como percebido e vivenciado pelos filhos, e o lugar do laço conjugal no projeto de vida destes filhos. Para atingir este objetivo, a investigação foi desenvolvida em duas etapas, articulando-se métodos quantitativos e qualitativos de pesquisa. Na primeira etapa, foi realizada uma pesquisa de levantamento, com jovens solteiros de ambos os gêneros, das camadas médias da população, para investigar a percepção dos filhos sobre o casamento de seus pais. Para a realização de tal levantamento, construímos o Questionário sobre a Conjugalidade dos Pais (QCP; Féres-Carneiro, 2003a), cujo estudo de validação encontra-se em fase final de desenvolvimento.

$\mathrm{Na}$ segunda etapa do estudo, foi realizada uma pesquisa qualitativa, utilizando-se entrevista semi-estruturada, com os jovens que, na primeira etapa da pesquisa, tinham avaliado a conjugalidade dos pais como muito satisfatória e com aqueles que avaliaram a conjugalidade dos pais como muito insatisfatória, buscando estudar a concepção e os ideais de casamento destes jovens, a partir do conceito de transmissão psíquica geracional (Kaës, 1998, 1993/2003a, 2003b, 2009). O objetivo último era o de explorar as possíveis relações existentes entre a percepção dos filhos sobre o casamento de seus pais e aquilo que o laço conjugal representava para eles.

$\mathrm{Na}$ maioria dos casos em que os jovens apresentaram um discurso de franca recusa à percepção da influência da conjugalidade dos pais sobre o lugar que esta ocupa em seus projetos de vida, a conjugalidade dos pais foi avaliada como muito insatisfatória. Considerou-se que esse resultado evidencia o quanto o não enfrentamento pelos pais de seus conflitos conjugais, e a manutenção de uma relação conjugal insatisfatória se expressam no processo de identificação e de diferenciação dos filhos e, consequentemente, na possibilidade de elaborar projetos de vida mais autônomos. O lugar que o casamento ocupa nos projetos de vida dos filhos parece estar relacionado com o modo como os jovens entrevistados se apropriaram de sua herança familiar e com o discernimento sobre os aspectos da conjugalidade dos pais que os influenciaram (Féres-Carneiro, Seixas, \& Ziviani, 2006; Féres-Carneiro, Ziviani, \& Magalhães, 2007; Magalhães \& Féres-Carneiro, 2007). 
A investigação seguinte, intitulada "Conjugalidades Contemporâneas: Um Estudo sobre os Múltiplos Arranjos Conjugais da Atualidade" (Féres-Carneiro \& Ziviani, 2009), utilizou uma metodologia qualitativa, entrevistando sujeitos heteroafetivos e homoafetivos, de ambos os gêneros, de diferentes arranjos conjugais contemporâneos: "ficar com", namoro, noivado, coabitação, união estável, casamento civil, recasamento, casamento em casas separadas e "poliamor" (Barker, 2005). As relações amorosas contemporâneas foram descritas pela maioria dos sujeitos de todos os arranjos como superficiais, efêmeras, descartáveis, e marcadas pela liberdade e pelo hedonismo (Bauman, 2003; Féres-Carneiro, 1998; Giddens, 1993). As características da vida contemporânea, como o estresse e a grande demanda das atividades profissionais apareceram, no discurso de homens e mulheres, como fatores, que interferem na qualidade e na frequência da vivência da sexualidade (Diniz \& Féres-Carneiro, 2012; Féres-Carneiro \& Ziviani, 2009).

A investigação "Parentalidades contemporâneas e a demanda de psicoterapia de família", que estamos desenvolvendo no momento, também foi desdobrada em dois estudos. Estamos finalizando as análises do primeiro estudo, no qual foram realizadas entrevistas, com mães, pais, filhos crianças e filhos adolescentes, pertencentes a famílias hetero e homoparentais, casadas, separadas, recasadas e monoparentais.

Constatamos, a partir do discurso dos entrevistados, que os pais estão mais presentes, participativos e envolvidos no cotidiano dos filhos, compartilhando com as mães os cuidados em relação a eles. Assim, esta nova forma de exercer a paternidade vai de encontro à figura do pai tradicional, concebido como provedor e disciplinador, para fazer surgir a figura do pai nutridor, que acolhe e satisfaz necessidades físicas e emocionais dos filhos. Os pais afirmam que estão exercendo estas novas funções com muita satisfação (Féres-Carneiro, Ziviani, Magalhães, \& Ponciano, 2013; Gomes \& Resende, 2004; Jablonski \& Féres-Carneiro, 1999; Lewis \& Dessen, 1999; Pereira \& Silva, 2006).

As mães, ao mesmo tempo em que falam de uma experiência de plenitude no exercício da maternidade, ressaltam também as responsabilidades e as dificuldades relacionadas aos cuidados com os filhos. Na medida em que despendem grande parte do tempo no trabalho, algumas se sentem culpadas e destacam a importância de passar um tempo de qualidade com os filhos. Apesar das preocupações e responsabilidades, as mães, assim como os pais em relação à paternidade, relatam sentir grande prazer e satisfação no exercício da maternidade (Badinter, 2011; Jablonski, 2007; Rocha-Coutinho, 2009; Zornig, 2010).

Tanto as crianças quanto os adolescentes descrevem a experiência de serem filhos/filhas como boa, evidenciando a existência de uma família democrática e igualitária, onde as relações são, cada vez mais, horizontais, reduzindo a possibilidade de conflitos entre pais e filhos, e promovendo mais intimidade e conforto para todos na família (Borges \& Magalhães, 2009; Gallagher, Féres-Carneiro, \& Henriques, 2013).

Percebe-se que no ambiente familiar pode ocorrer uma flexibilidade suficiente, que instiga os membros da família envolvidos a questionarem as regras instituídas e, com isso, facilitarem a reformulação das mesmas e em consequência fomentar a aquisição de mais autonomia (Henriques, Féres-Carneiro, \& Ramos, 2011; Ponciano \& Féres-Carneiro, 2014).

Verifica-se a existência de um interjogo, uma prática intersubjetiva, na qual os sujeitos funcionam em reciprocidade e se influenciam em diversos planos. Revelou-se a capacidade de reinvenção, instigada por movimentos de não conformismo ao que está instituído, possibilitando argumentações que visam a renegociar os acordos da relação. Filhos e pais pareceram estar, constantemente, esperando os desdobramentos das investidas em direção ao questionamento de um limite: uns transgridem e outros permitem veladamente a transgressão. Dessa forma, a partir de sentimentos comuns circulantes, é possível dizer que a aquisição de autonomia dos filhos promove a autonomia dos pais, o que constitui um processo de diferenciação de todos (Henriques et al., 2011; Ramos, 2006).

Assim, entendeu-se a autonomia como um processo interindividual, onde todos os mem- 
bros da família se envolvem, e como um conjunto de experimentações na prática parental cotidiana atual. A vivência deste processo, contudo, é transpassada por medos, inquietações, hesitações e incertezas, tanto nos pais como nos filhos. Estes sentimentos podem revelar as dimensões da insegurança e do desamparo, no confronto com o mundo, sobretudo nas crianças e nos adolescentes. Por outro lado, os "novos pais" destas "novas crianças" e "novos adolescentes" expressaram que têm projetos educativos, elaborados a partir de seus temores da violência, que caracteriza o momento atual (Caillé, 2003; Zannetti \& Gomes, 2012).

Estas novas crianças e adolescentes, frutos dos desdobramentos dos processos da desierarquização na família, apresentam-se, tal como afirma Racamier (1995), com algumas dificuldades nas relações sociais e uma dependência crescente da mediação dos pais em relação ao ambiente, apesar de mais autônomas, segundo o olhar dos pais e dos adultos que as cercam.

Ao serem questionados sobre o que esperam dos filhos, a grande maioria dos pais e mães entrevistados aponta a vida profissional como central nas expectativas para o futuro. Apenas o desempenho é levado em conta, por conseguinte, a pressão por resultados se esgota até as últimas consequências. Em um contexto de mudanças aceleradas e incertezas quanto ao futuro, o alto investimento em práticas para o aperfeiçoamento pessoal e para a sobrevivência das próximas gerações apresenta-se como salvaguarda no presente. Resta saber se tais práticas sustentam uma existência com sentido, ou como diria Winnicott (1971), uma vida que vale a pena ser vivida.

A maior parte dos filhos, ao falar sobre o futuro, discorre sobre a vida profissional, confirmando as expectativas dos pais. Tanto as crianças quanto os adolescentes entrevistados se mostram inquietos com a escolha da profissão e as possibilidades de carreiras que ela oferece. Os filhos mencionam formações prolongadas como meio de encontrar um lugar no universo do trabalho. O anseio de casar e ter filhos e/ou constituir uma família não aparece de forma proeminente no discurso dos filhos, de forma que os projetos para o futuro se inscrevem, sobretu- do, no plano profissional (Féres-Carneiro et al., 2006; Féres-Carneiro et al., 2007; Féres-Carneiro et al., 2013).

Estamos, no momento, iniciando o desenvolvimento do segundo estudo, referente à demanda de psicoterapia de família, nas diversas configurações familiares contemporâneas, e sua relação com o exercício da parentalidade. Este estudo está sendo desenvolvido no Serviço de Psicologia Aplicada da PUC-Rio e contempla as entrevistas preliminares e as sessões de avaliação familiar, realizadas por meio da aplicação da Entrevista Familiar Estruturada (Féres-Carneiro, 2005) e do Arte-Diagnóstico Familar (Kwiatkowska, 1975).

No momento estamos, também, concluindo a pesquisa de validação do "Questionário sobre a conjugalidade dos pais" (QCP; Féres-Carneiro, 2003a), construído para o desenvolvimento do estudo sobre o lugar que o casamento ocupa no projeto de vida dos jovens solteiros (que relatamos anteriormente). Vários estudos já foram realizados com o QCP no percurso da sua validação (Féres-Carneiro et al., 2006; Ziviani, Féres-Carneiro, \& Magalhães, 2009, 2011, 2012).

O estudo de validação, que se encontra em fase de conclusão, pretende verificar a relação do Questionário sobre a Conjugalidade dos Pais (QCP; Féres-Carneiro 2003a) com Inventário de Habilidades Sociais Conjugais (IHSC-Villa \& Del-Prette; Villa \& Del-Prette 2012), visando a obter evidências sobre a validade convergente e a validade divergente do QCP-Pais face ao IHSC.

A trajetória da evolução do QCP como um todo, com o objetivo de se transformar em um teste psicológico, que atenda aos critérios estabelecidos pelo Conselho Federal de Psicologia, tem sido pautada, quanto ao conceito de validade, pelo o que é preconizado por Primi, Muniz, e Nunes (2009). Essa trajetória caracteriza-se pela progressiva articulação da teoria psicométrica, buscando explicar certos resultados, com base na teoria psicanalítica freudiana e em seus desdobramentos atuais, alicerçados na psicanálise de grupo e na teoria da transmissão psíquica entre gerações (Freud, 1914/1996; Kaës, 1993/2003a, 1998, 2009; Kaës, Pinel, \& Kernberg, 2012). 
No estudo atual, buscamos avançar quanto aos impasses teóricos e metodólogicos impostos pelos estudos anteriores. A estrutura da matriz de covariância do Questionário sobre a Conjugalidade dos Pais (QCP) foi replicada em uma nova coleta de dados, e constamos, mais uma vez, as excelentes propriedades psicométricas do instrumento, com um bom índice de consistência interna, e bons índices de ajustamento. Constamos também a existência de dois fatores, denominados de "conjugalidade explícita" e "conjugalidade implícita". O primeiro faz referência à percepção geral da conjugalidade dos pais. $\mathrm{O}$ segundo emerge do primeiro fator, e está relacionado com a presença de itens opostos, indicando a ambivalência real e típica da conjugalidade (Freud, 1914/1996; Kaës, 1993/2003a; Machado \& Féres-Carneiro, 2012).

Enfatizamos a nossa posição teórica, destacando a teoria da transmissão psíquica geracional (Kaës, 1993/2003a), nossa posição metodológica, com a "lei da vizinhança" (Guttman, 1955); e a nossa posição epistemológica hegeliana (Hegel, 1812/1972), abrindo mão de um purismo tradicional na análise dos dados, para propor um diálogo entre duas áreas, aparentemente incompatíveis: a Psicometria e a Psicanálise e, assim, reafirmar, mais uma vez, nosso propósito de buscar articulações teóricas na pesquisa e na prática psicológica.

Finalmente, gostaria de ressaltar que nossa proposta de construção de articulações teórico-técnicas não desconsidera a importância da consistência entre teoria e prática, e a coerência com uma determinada posição epistemológica. Entretanto, dentro de uma mesma posição epistemológica, incontáveis modelos de atendimento são possíveis. Como ressalta Maturana (1990), há diversos modos de fazer terapia e estes modos distintos têm a ver com as distintas características dos terapeutas. Para o autor, haverá tantas propostas terapêuticas quantos forem os terapeutas.

No início da minha fala, ressaltei minhas características de negociadora, articuladora, conciliadora de posições, "radical de centro", como dizia, de modo muito carinhoso, o Marcio, meu marido, que era de Pontal, cidade vizinha à Ri- beirão, e que faleceu no ano passado, depois de termos compartilhado 41 anos de nossas vidas. Assim, não é por acaso que exerço há 42 anos as funções de docente-pesquisadora e de psicóloga clínica, concebendo tais funções como indissociáveis.

Não é por acaso que, no exercício da clínica, escolhi ser psicoterapeuta de família e casal, e que, como clínica-pesquisadora proponho como vários outros autores de projeção na área de família e casal (Flaskas \& Pocock, 2009; Lemaire, 1984; Nicollò, 1988; Willi, 1982) - a articulação de diferentes abordagens teórico-técnicas. O mais importante é que o psicoterapeuta tenha uma postura ética, lançando mão de todas as possibilidades teórico-técnicas ao seu alcance, para intervir de modo a alcançar o melhor benefício terapêutico para os seus pacientes.

E é neste movimento dialético que se dá da clínica para a pesquisa e da pesquisa que, de volta para clínica, pode modificá-la, que pretendo continuar construindo múltiplas articulações: articulações entre diferentes saberes, articulações entre diferentes abordagens teórico-técnicas, articulações entre diferentes sujeitos que se constroem e se reconstroem na intersubjetividade, buscando ver, nas diferenças, muito mais possibilidades de as mesmas se complementarem do que de se excluírem mutuamente. Esta proposta vai ao encontro do tema "Onde a diversidade se encontra", escolhido pela SBP para a Reunião Anual deste ano. Que o encontro das diferenças nesta nossa $44^{\mathrm{a}}$ Reunião Anual possa contribuir para a construção de uma Psicologia cada vez mais plural e comprometida com a excelência acadêmica a que todos nos propomos.

Muito obrigada!

\section{Referências}

Badinter, E. (2011). O conflito: A mulher e a mãe. Rio de Janeiro, RJ: Record.

Barker, M. (2005). This is my partner, and this is my partner's partner: Constructing a polyamorous identity in a monogamous world. Journal of Constructivist Psychology, 18, 75-88. doi:10.1080/10720530590523107

Bauman, Z. (2003). Comunidade: A busca por segurança no mundo atual. Rio de Janeiro, RJ: 
Zahar.

Borges, C. C., \& Magalhães, A. S. (2009). Transição para a vida adulta: Autonomia e dependência na família. Psico, 40(1), 42-49.

Caillé, P. (2003). Être parent aujourd' hui: performance d' un role ou vécu d' un état. Dilemmes et contradiction de la position parentale contemporaine. Neuropsychiatrie de l'Enfance et de l' Adolescence, 51, 137-144.

Diniz, G., \& Féres-Carneiro, T. (2012). Casamento e família: Uma reflexão sobre desafios da conjugalidade contemporânea. In T. Camargo Viana, G. Diniz, L. C. Fortunato, \& V. Zamello, Psicologia Clínica e cultura contemporânea (pp. $443-$ 462). Brasília, DF: Liber Livro.

Féres-Carneiro, T. (1975). Entrevista Familiar Estruturada: Um novo método clínico de avaliação das relações familiares (Dissertação de mestrado, Programa de Pós-Gradução em Psicologia Clínica, Pontifícia Universidade Católica do Rio de Janeiro, RJ, Brasil).

Féres-Carneiro, T. (1980). Psicoterapia de casal e suas repercussões no comportamento dos filhos. Arquivos Brasileiros de Psicologia, 32(4), 5160.

Féres-Carneiro, T. (1981). Entrevista Familiar Estruturada: Sua consistência, validade e aplicabilidade em Psicologia Clínica (Tese de doutorado, Programa de Pós-Graduação em Psicologia Clínica, Pontifícia Universidade Católica de São Paulo, SP, Brasil).

Féres-Carneiro, T. (1983). Família: Diagnóstico e terapia. Rio de Janeiro, RJ: Zahar.

Féres-Carneiro, T. (1987). Aliança e sexualidade no casamento e no recasamento contemporâneo. Psicologia: Teoria e Pesquisa, 3(3), 250-261.

Féres-Carneiro, T. (1993). Academia e profissão em Psicologia Clínica. Psicologia: Reflexão e Crítica, 12, 103-105.

Féres-Carneiro, T. (1995). Terapia de casal: Ruptura ou manutenção do casamento? Temas em Psicologia, 2, 37-52.

Féres-Carneiro, T. (1996). Terapia familiar: Das divergências às possibilidades de articulação dos diferentes enfoques. Psicologia: Ciência e Profissão, 16, 38-42. doi:10.1590/S141498931996000100007

Féres-Carneiro, T. (1997). Escolha amorosa e in- teração conjugal na heterossexualidade e na homossexualidade. Psicologia: Reflexão $e$ Crítica, 10(2), 351-368. doi:10.1590/S010279721997000200012

Féres-Carneiro, T. (1998). Casamento contemporâneo: $\mathrm{O}$ difícil convívio da individualidade com a conjugalidade. Psicologia: Reflexão $e$ Crítica, 11(2), 379-394. doi:10.1590/S010279721998000200014

Féres-Carneiro, T. (1999). Conjugalidade: Um estudo sobre as diferentes dimensões da relação amorosa heterossexual e homossexual. In T. Féres-Carneiro, Casal e família: Entre a tradição e a transformação (pp. 96-117). Rio de Janeiro, RJ: Nau.

Féres-Carneiro, T. (2001). Casamento contemporâneo: Construção da identidade conjugal. In $\mathrm{T}$. Féres-Carneiro, Casamento e família: Do social à clínica (pp. 67-80). Rio de Janeiro, RJ: Nau.

Féres-Carneiro, T. (2003a). Conjugalidade dos pais e projeto dos filhos frente ao laço conjugal (Projeto de pesquisa submetido ao Conselho Nacional de Pesquisa). Rio de Janeiro: Pontifícia Universidade Católica do Rio de Janeiro, Departamento de Psicologia.

Féres-Carneiro, T. (2003b). Separação: O doloroso processo de dissolução da conjugalidade. Estudos de Psicologia (Natal), 8(3), 367-374.

Féres-Carneiro, T. (2003c). Construção e dissolução do laço conjugal na terapia de casal. In T. Féres-Carneiro, Família e casal: Arranjos e demandas contemporâneas (pp. 201-214). Rio de Janeiro, RJ: Editora da Pontifícia Universidade Católica do Rio de Janeiro.

Féres-Carneiro, T. (2005). Entrevista familiar estruturada: Um método clínico de avaliação das relações familiares. São Paulo, SP: Casa do Psicólogo.

Féres-Carneiro, T. (2008). Clínica de família e casal: Narrando quatro décadas de pesquisa. Revista Brasileira de Terapia Familiar, 1(1), 91-101.

Féres-Carneiro, T., Seixas, A., \& Ziviani, C. (2006). Conygalidad de los padres y proyectos de vida de los hijos frente al matrimonio. Cultura y Educación, 18(1), 95-108.

Féres-Carneiro, T., \& Ziviani, C. (2009). Conjugalidades contemporâneas: Um estudo sobre os múltiplos arranjos conjugais da atualidade. In T. Féres-Carneiro, Casal e família: Permanências 
e rupturas (pp. 83-107). São Paulo, SP: Casa do Psicólogo.

Féres-Carneiro, T., Ziviani, C., \& Magalhães, A. S. (2007). Questionário sobre a conjugalidade dos pais como instrumento de avaliação. In T. Féres-Carneiro, Família e casal: Saúde, trabalho e modos de vinculação (pp. 251-268). São Paulo, SP: Casa do Psicólogo.

Féres-Carneiro, T., Ziviani, C., Magalhães, A. S., \& Ponciano, E. L. T. (2013). Ser pai(mãe), ser filho(a): A resolução de conflitos em famílias contemporâneas casadas. In T. Féres-Carneiro, Casal e família: Transmissão, conflito e violência (pp. 73-98). São Paulo, SP: Casa do Psicólogo.

Flaskas, C., \& Pocock, D. (2009). Systems and psychoanalysis - Contemporary integrations in family therapy. London: Karnac Books.

Foucault, M. (1977). História da sexualidade I. Rio de Janeiro, RJ: Graal.

Freud, S. (1996). Sobre o narcisismo: Uma introdução. In S. Freud, Edição standard brasileira das obras psicológicas completas de Sigmund Freud (J. Salomão, Trad., Vol. XIV, pp. 75-108). Rio de Janeiro, RJ: Imago. (Original publicado em 1914)

Gallagher, I. M., Féres-Carneiro, T., \& Henriques, C. R. (2013). Planos para o futuro: Percepções de filhos adultos coabitantes com os pais. Revista da SPAGESP, 14(2), 4-18.

Giddens, A. (1993). A transformação da intimidade sexualidade, amor e erotismo nas sociedades modernas. São Paulo, SP: Editora da Universidade Estadual Paulista "Júlio de Mesquita Filho".

Gomes, A. J. D. S., \& Resende, V. D. R. (2004). O pai presente: $\mathrm{O}$ desvelar da paternidade em uma família contemporânea. Psicologia: Teoria $e$ Pesquisa, 20(2), 119-125.

Guttman, L. (1955). A new approach to factor analysis: The radex. In P. Lazarsfeld (Ed.), Mathematical thinking in the social sciences $\left(2^{\text {nd }}\right.$ Rev. Ed., pp. 258-348). Glencoe, Scotland: The Free Press.

Hegel, G. W. F. (1972). Science de la logique. Premier tome, premier livre. L'Être (P.-J. Labarrière \& G. Jarczyk, Trans.). Paris: Aubier Montaigne. (Original publicado em 1812)

Henriques, C. R., Féres-Carneiro, T., \& Ramos, E.
(2011). Ajustes entre pais e filhos adultos coabitantes: Limite e transgressão. Psicologia em Estudo, 16(4), 531-539. doi:10.1590/S141373722011000400004

Jablonski, B. (1998). Até que a vida nos separe: A crise do casamento contemporâneo. Rio de Janeiro, RJ: Agir.

Jablonski, B. (2007). O cotidiano do casamento contemporâneo: A difícil e conflitiva divisão de tarefas. In T. Féres-Carneiro, Família e casal: Saúde, trabalho e modos de vinculação (pp. 203-228). São Paulo, SP: Casa do Psicólogo.

Jablonski, B., \& Féres-Carneiro, T. (1999). Identidade masculina e o exercício da paternidade: De onde viemos e para onde vamos. In T. Féres-Carneiro, Casal e família: Entre a tradição e a transformação (pp. 55-69). Rio de Janeiro, RJ: Nau.

Kaës, R. (1998). Os dispositivos psicanalíticos e as incidências da geração. In A. Eiguer (Ed.), $A$ transmissão do psiquismo entre gerações (pp. 55-19). São Paulo, SP: Unimarco.

Kaës, R. (2003a). Le groupe et le sujet du groupe. Paris: Dunod. (Original publicado em 1993)

Kaës, R. (2003b). O intermediário na abordagem psicanalítica da cultura. Psicologia USP, 14(3), 15-34.

Kaës, R. (2009). Les alliances inconscientes. Paris: Dunod.

Kaës, R., Pinel, J. P., \& Kernberg, O. F. (2012). Souffrance et psychopathologie des liens institutionnels. Paris: Dunod.

Kwiatkowska, H. Y. (1975). Instruções para conduzir sessões de Arte-Diagnóstico Familiar. Manuscrito não publicado, Pontifícia Universidade Católica do Rio de Janeiro, RJ, Brasil.

Lemaire, J. (1984). Le couple, sa vie, sa mort. Paris: Payot.

Lewis, C., \& Dessen, M. A. (1999). O pai no contexto familiar. Psicologia: Teoria e Pesquisa, 15(1), 9-16.

Machado, R. N., \& Féres-Carneiro, T. (2012). A parentalidade adotiva em questão. Trieb, 11(2), 103-122.

Magalhães, A. S. (1993). Individualismo e conjugalidade: Um estudo sobre o casamento contemporâneo (Dissertação de mestrado, Programa de Pós-Gradução em Psicologia Clínica, Pontifícia 
Universidade Católica do Rio de Janeiro, RJ, Brasil).

Magalhães, A. S., \& Féres-Carneiro, T. (2007). Transmissão psíquica geracional: Um estudo de caso. In T. Féres-Carneiro, Família e casal: Saúde, trabalho e modos de vinculação (pp. 341-364). São Paulo, SP: Casa do Psicólogo.

Maturana, H. (1990). Biología de la cognición y epistemología. Temuco, Chile: Universidad de la Frontera.

Nicollò, A. M. (1988). Soigner à l'intérieur de l'autre: notes sur la dynamique entre l'individu et la famille. Roma, Italia: Mimeo.

Pereira, R. C., \& Silva, C. M. (2006). Nem só de pão vive o homem. Sociedade e Estado, 21, 667-680.

Piccinini, C. A. (1996). Sobre o relacionamento entre pesquisador e profissional em Psicologia. Coletâneas da ANPEPP, 1(8), 31-40.

Ponciano, E. L. T., \& Féres-Carneiro, T. (2014). Relação pais-filhos na transição para a vida adulta, autonomia e relativização da hierarquia. Psicologia: Reflexão e Crítica, 27(2), 388-397. doi:10.1590/1678-7153.201427220

Primi, R., Muniz, M., \& Nunes, C. H. S. S. (2009). Definições contemporâneas de validade de testes psicológicos. Avanços e Polêmicas em Avaliação Psicológica, 1, 243-265.

Racamier, P. C. (1995). L'Inceste et l' incestuel. Paris: Apsygee.

Ramos, E. (2006). As negociações no espaço doméstico: Construir a "boa distância" entre pais e jovens adultos "coabitantes". In M. L. Barros (Ed.), Família e gerações (pp. 39-63). Rio de Janeiro, RJ: Fundação Getúlio Vargas.

Rocha-Coutinho, M. (2009). De volta ao lar: Mulheres que se afastaram de uma carreira profissional para melhor se dedicar aos filhos. In $\mathrm{T}$. Féres-Carneiro, Casal e família: Permanências e rupturas (pp. 219-235). São Paulo, SP: Casa do Psicólogo.

Villa, M., \& Del Prette, Z. (2012). Inventário de Ha- bilidades Sociais Conjugais (IHSC-Villa \& Del-Prette): Manual de aplicação, apuração e interpretação. São Paulo, SP: Casa do Psicólogo.

Willi, J. (1982). Couples in collusion. New York: Jason Aronson.

Winnicott, D. W. (1971). O brincar e a realidade. Rio de Janeiro, RJ: Imago.

Zannetti, S. A. S., \& Gomes, I. C. (2012). A fragilização das funções parentais na família contemporânea: Determinantes e consequências. Temas em Psicologia, 19(2), 491-502.

Ziviani, C., Féres-Carneiro, T., \& Magalhães, A. S. (2009). A conjugalidade dos pais percebida pelos filhos: Questionário de avaliação. In T. Féres-Carneiro, Casal e família: Permanências e rupturas (pp.157-168). São Paulo, SP: Casa do Psicólogo.

Ziviani, C., Féres-Carneiro, T., \& Magalhães, A. S. (2011). Sons and daughters' perception of parents as a couple: Distinguishing characteristics of a measurement model. Psicologia: Reflexão e Crítica, 24, 28-39. doi:10.1590/S010279722011000100005

Ziviani, C., Féres-Carneiro, T., \& Magalhães, A. S. (2012). Pai e mãe na conjugalidade: Aspectos conceituais e validação de construto. Paidéia (Ribeirão Preto), 22(52), 165-176. doi:10.1590/ S0103-863X2012000200003

Zornig, S. M. A. J. (2010). Tornar-se pai, tornar-se mãe: O processo de construção da parentalidade. Tempo Psicanalítico, 42(2), 453-470. 